\title{
UJI EKSPERIMETAL TRAJECTORY TRACKING PADA ROBOT PENJINAK BOM
}

\author{
Randis \\ Teknik Mesin Alat Berat, Politeknik Negeri Balikpapan \\ E-mail: randis@poltekba.ac.id
}

\begin{abstract}
The problem of terrorism is engulfing the world has implications for the war against global terrorism. The creation of the bomb disposal robot that was able to defuse the bomb intended to create a reliable basis in all areas of security and service to humanity. The aim of this research is calculate of error trajectory tracking bomb disposal robot. This bomb disposal robot uses a caterpillar wheel using two motors with an independent control system. In addition, the robot is tested by using wireless control and navigation with line follower system. Testing is done by making two tracks on the floor surface and then test the navigation system with manual control involving two operators, then the authors implement the program control system bomb squad robot using the line sensor. The conclusion that can be decided from this research is control system by using wireless and line follower system can be used interchangeably where the value of the error for line follower system is much smaller compared with the system direct control (Bluethooth).
\end{abstract}

Keywords: Bomb disposal robot, Trajectory tracking , Control System.

\begin{abstract}
Abstrak
Masalah terorisme yang melanda dunia berimplikasi pada peperangan terhadap terorisme secara global. Penciptaan robot penjinak bom yang mampu menjinakkan bom secara handal dimaksudkan untuk menciptakan keamanan pada seluruh bidang serta pelayanan terhadap umat manusia. Tujuan dari penelitian ini adalah untuk menghitung error trajectory tracking pada robot penjinak bom. Robot penjinak bom ini menggunakan roda caterpillar dengan menggunakan dua motor dengan sistem kendali independen. Selain itu robot diuji cobakan dengan menggunakan kendali wireless dan navigasi denganlLine follower sistem. Pengujian dilakukan dengan membuat dua buah track lintasan pada permukaan lantai selanjutnya menguji sistem navigasi dengan kontrol manual melibatkan dua operator, kemudian penulis mengimplementasikan program sistem kendali robot penjinak bom menggunakan sensor garis. Kesimpulan yang dapat diperoleh dari penelitian ini adalah sistem kontrol dengan menggunakan wireless dan line follower dapat digunakan secara bergantian dimana nilai error untuk line follower sistem jauh lebih kecil dibanding dengan menggunakan sistem kontrol langsung (bluetooth).
\end{abstract}

Kata Kunci: Robot penjinak bom, Trajectory tracking, Sistem kontrol

\section{PENDAHULUAN}

Perkembangan teknologi yang semakin pesat khususnya dalam bidang perkembangan robot yang menjadikan kualitas kehidupan manusia semakin tinggi. Robot dikembangkan tidak lain untuk mempermudah pekerjaan manusia. Dalam dunia robot terdapat kategori mobile robot. Mobile robot adalah robot yang dapat bergerak atau berpindah tempat dan dapat dikendalikan secara otomatis atau manual (Suradana \& Sudiarsa, 2013)

Salah satu tujuan dari mobile robot adalah pengembangan perangkat yang bisa mobile pada lingkungan yang padat penduduk dan menawarkan berbagai pelayanan kepada manusia (Schulz,
Burgard, Fox, \& Cremers, 2001). Minat terhadap kontrol pelacakan mobile robot telah meningkat dengan berbagai kontribusi teoretis dan praktis yang dibuat. Khususnya, umpan balik linearisasi yang telah menarik banyak minat penelitian dalam teori kontrol nonlinier terbaru, dan beberapa teknik telah digunakan dalam kontrol robot bergerak (Sun, 2005). Sementara penelitian menyebutkan bahwa menstabilkan mobile robot dengan menggunakan umpan balik yang tetap pada umumnya cukup sulit, maka beberapa penelitian menggunakan teknik kontrol otomatis yang banyak digunakan pada industri pertambangan, eksplorasi ruang angkasa, pengawasan militer dan sistem keamanan. (Lee, Lin, 
Lim, \& Lee, 2009; Leana \& Saju, 2016; Matraji, AlDurra, Haryono, Al-Wahedi, \& Abou-Khousa, 2018)

Beberapa maksud dan tujuan dilakukanya penguajian error trajectory tracking pada robot diantaranya untuk misi dan tugas yang krusial, dibutuhkan robot dengan tingkat error lintasan yang kecil agar dapat mencapai tujuan dengan waktu yang efektif dan efisien serta menjamin misi dapat diselesaikan dengan baik (Randis \& Akbar, 2017; Syam, Mappaitta, \& Hidayat, 2015). Untuk mengetahui kemampuan kontrol secara manual dengan menggunakan operator maka test ini diperlukan untuk memastikan bahwa eror yang terjadi tidak terlampau besar dan untuk membandingkan tingkat kemahiran operator dengan dengan eror yang dihasilkan (Syam \& Ohoiwutun, 2013).

Penelitian yang dilakukan yaitu menguji robot penjinak bom yang merupakan kombinasi mobile robot dan robot manipulator untuk menjejal dua buah lintasan dengan menggunakan dua operator yang dikontrol dengan kontrol manual, selanjutnya robot juga diuji dengan sistem kontrol otomatis menggunakan sensor garis, untuk membandingkan besarnya error yang terjadi untuk kedua sistem yang diterapkan pada robot penjinak bom.

\section{METODE PENELITIAN}

a. Objek Penelitian

Pada penelitian ini menggunakan robot penjinak bom yang ditunjukkan pada gambar 1. Adapun spesifkasi sebagai dari robot adalah:

$\begin{array}{ll}\text { Panjang robot } & : 45 \mathrm{~cm} \\ \text { Lebar robot } & : 25 \mathrm{~cm} \\ \text { Panjang antara poros roda } & : 27 \mathrm{~cm} \\ \text { Panjang Aktuator } & : 40 \mathrm{~cm} \\ \text { Berat Robot } & : 8 \mathrm{~kg} \\ \text { Diameter roda } & : 12 \mathrm{~cm} \\ \text { Power Motor pengerak } & : 12 \mathrm{volt} \\ \text { Power mikrokontroller } & : 9 \mathrm{volt}\end{array}$

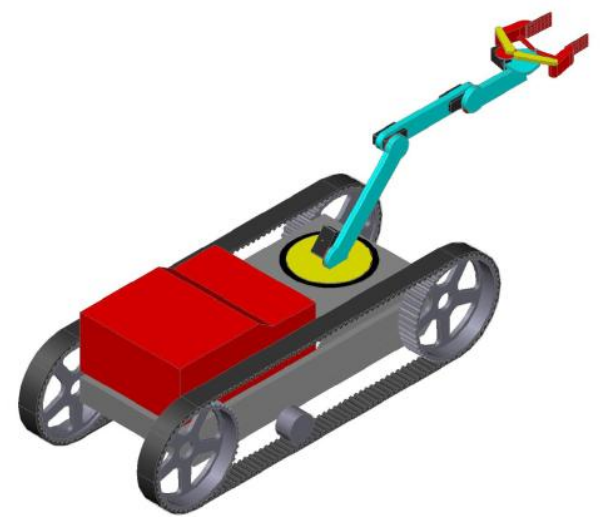

Gambar 1. Robot Penjinak Bom Sebagai Objek Penelitian

\section{b. Diagram Blok}

Diagram blok yang digunakan pada penelitian ini merupakan diagram blok close loop dan ditunjukkan pada gambar 2 dan 3. Diagram blok dengan sistem control manual mengandalkan pengamatan operator untuk memberikan umpan balik untuk memberikan input ke sistem agar posisi actual robot dapat berada pada setpoint yang telah ditentukan sehingga nilai error yang diperoleh juga bisa bernilai kecil. Sedangkan untuk robot dengan sistem otomatis menggunakan sensor garis, pembacaan sensor akan memberikan feedback kesitem sehingga controller yang telah deprogram akan selalu menggerakkan motor untuk mendapatkan posisi robot sesuai dengn set point yang telah ditentukan

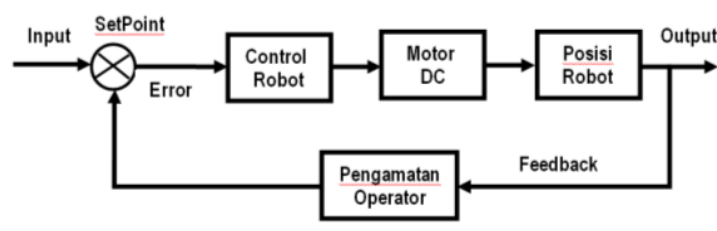

Gambar 2. Diagram Blok Control Manual

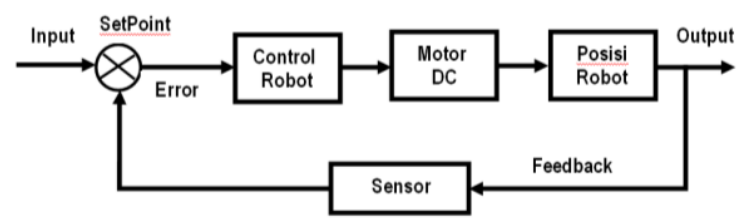

Gambar 3. Diagram Blok Control Otomatis

\section{c. Perancangan Penelitian}

Perancangan sistem elektronik yang mengatur dan mengendalikan robot secara manual dan otomatis dengan menggunakan sensor garis diperlihatkan pada gambar 3 dan 4. Prinsip kerja robot penjinak bom dengan menggunakan sistem line follower memanfaatkan sensor photodiode berserta LED superbright diteruskan pada rangkaian pengkondisi sinyal (komparator). Rangkaian komparator digunakan untuk membandingkan nilai yang dibaca sensor photodiode dengan nilai referensi komparator. Hasil dari komparator selanjutnya menjadi data masukan bagi mikrokontroller. Setelah kondisi logika diproses oleh mikrokontroller maka output akan di teruskan ke rangkaian driver selanjutnya driver akan menggerakan motor pada robot.

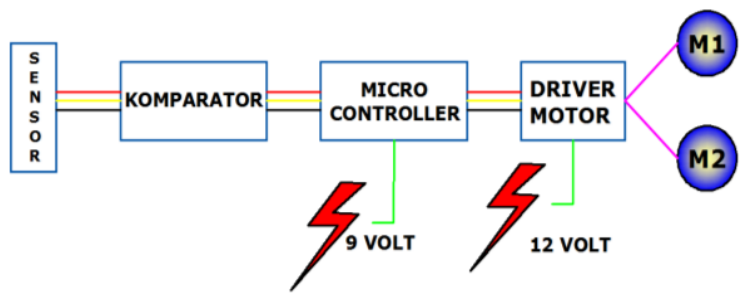

Gambar 4. Perancangan sistem Otomatis 
Sementara perancangan sistem pada robot penjinak bom dengan sistem manual menggunakan remote control dengan joystick sebagai transmitter yang terhubung dengan module bluethooth sebagai receiver yang terpasang terkonneksi dengan controller dan driver motor untuk mengatur pergerakan motor dc untuk menggerakkan robot maju, mundur ataupun berbelok.

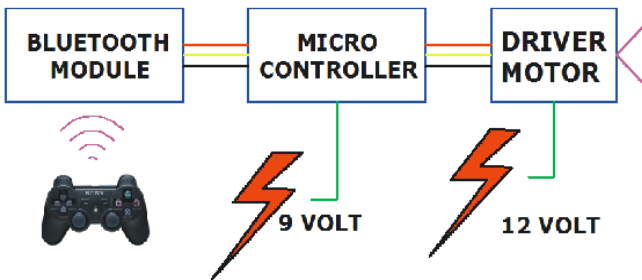

Gambar 5. Perancangan sistem Manual

\section{HASIL DAN PEMBAHASAN}

Pada penelitian ini menggunakan 2 buah lintasan. Lintasan pertama, dilakukan percobaan error trajectory tracking dengan dua operator yang berbeda. Adapun bentuk lintasannya sebagai berikut: a. Lintasan 1

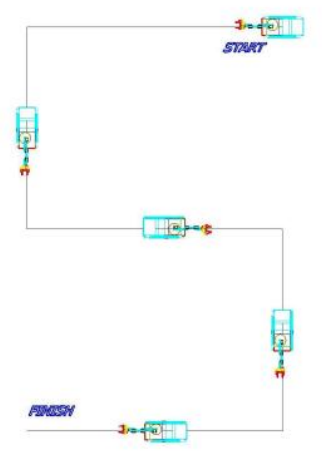

Gambar 36 : Lintasan Persegi Sumber : Dokumen Pribadi (2013).

\section{Gambar 6. Track Lintasan 1}

Pada lintasan Pertama, mobile manipulator robot memulai pada lintasan start. Mobile robot bergerak mendatar sejauh $374 \mathrm{~cm}$ kemudian berbelok ke arah kiri sebesar 90 derajat lalu bergerak mendatar sejauh $374 \mathrm{~cm}$ kemudian berbelok lagi ke arah kiri sebesar 90 derajat lalu bergerak pada lintasan yang mendatar sejauh $374 \mathrm{~cm}$ kemudian berbelok ke arah kanan sebesar 90 derajat lalu bergerak mendatar sejauh 374 $\mathrm{cm}$, dan yang terakhir berbelok ke arah kanan sebesar 90 derajat lalu bergerak mendatar sejauh $374 \mathrm{~cm}$ sampai mencapai garis finish.

Hasil trajectory tracking pada mobile robot penjinak bom diperlhatkan pada gambar 7. Pada grafik terlihat bahwa error terbesar pada operator pertama dan kedua terjadi pada belokan kanan yang terakhir dengan sudut $90^{\circ}$. Hal tersebut disebabkan karena pada saat robot berbelok, robot melakukan transformasi (perubahan posisi) dari vertical ke horizontal membetuk sudut 90 yang menjauh dari garis lintasan sehingga mengakibatkan nilai error yang besar.

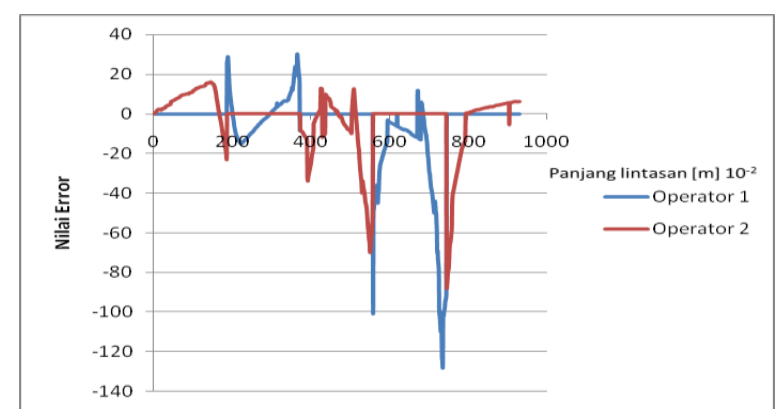

\section{Gambar 7. Grafik Error Pada Lintasan 1}

Pada grafik diatas terlihat pula lintasan error untuk lintasan pertama. diimana error terbesar untuk operator pertama yaitu pada nilai $-130 \mathrm{~cm}$ dan error terbesar untuk operator ke-dua ada pada nilai $-92 \mathrm{~cm}$. Nilai error yang besar untuk kedua operator masingmasing terjadi pada belokan kanan yang terakhir sedangkan untuk nilai error yang terkecil terjadi pada saat robot melewati track yang lurus pada lintasan.

Rata-rata error pada lintasan 1 oleh operator 1 dan 2 yaitu:

$$
\begin{aligned}
& e_{\text {tot }}=\sqrt{\frac{\left(\sum_{0}^{n} e x\right)^{2}+\left(\sum_{0}^{n} e y\right)^{2}}{n}} \\
& e_{t o t}=22.83 \mathrm{~cm}
\end{aligned}
$$

b. Lintasan 2

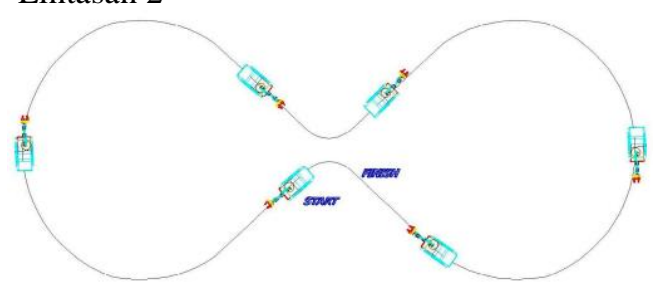

Gambar 8. Track Lintasan 2

Pada lintasan kedua, robot mobile manipulator memulai pada lintasan start. Mobile robot bergerak memutar melingkar sampai mencapai garis finish. Pada track lintasan yang kedua ini, terdapat 2 variasi belokan dengan radius yang berbeda sehingga membutuhkan operator yang handal untuk mendapatkan nilai error yang kecil. 


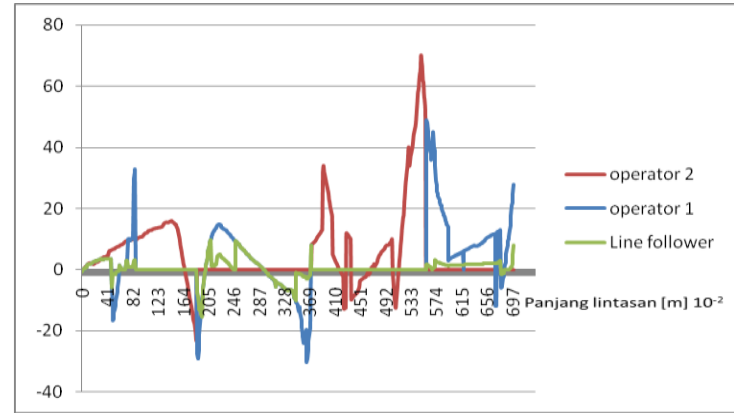

Gambar 9. Grafik Error pada Lintasan 2

Pada grafik diatas terlihat bahwa nilai error tebesar baik untuk operator 1 maupun operator 2, yaitu pada saat melewati tikungan dengan radius besar menuju ke tikungan dengan radius kecil. Hal tersebut disebabkan karena robot sangat sulit berbelok dengan radius belokan yang kecil sehingga robot keluar dari garis yang telah di buat, dengan demikian nilai error yang terjadi juga akan bernilai besar pula. Sedangkan untuk line follower, terlihat bahwa nilai error tebesar terjadi pada saat tikungan dengan radius kecil.

Pada grafik diatas terlihat pula lintasan error untuk lintasan pertama. diimana error terbesar untuk operator pertama yaitu pada nilai $70 \mathrm{~cm}$ dan error terbesar untuk operator ke-dua ada pada nilai $49 \mathrm{~cm}$, sedangkan untuk line follower nilai error terbesr bernilai 9,8 cm. Nilai error yang besar untuk kedua operator masing-masing terjadi pada belokan kanan yang terakhir sedangkan untuk nilai error yang terkecil terjadi pada saat robot melewati track yang lurus pada lintasan, sedangkan untuk line follower, terjadi pada saat melewati tikungan dengan radius kecil.

Rata-rata error pada lintasan 2 oleh operator 1 dan 2 yaitu:

$$
\begin{gathered}
e_{\text {tot }}=\sqrt{\frac{\left(\sum_{0}^{n} e x\right)^{2}+\left(\sum_{0}^{n} e y\right)^{2}}{n}} \\
e_{\text {tot }}=20.25 \mathrm{~cm}
\end{gathered}
$$

Rata-rata error pada lintasan 2 dengan line follower yaitu:

$$
\begin{aligned}
e_{\text {tot }} & =\sqrt{\frac{\left(\sum_{0}^{n} e x\right)^{2}+\left(\sum_{0}^{n} e y\right)^{2}}{n}} \\
e_{\text {tot }} & =3.55 \mathrm{~cm}
\end{aligned}
$$

\section{SIMPULAN}

1. Pada lintasan 1 , nilai error terbesar yaitu $\mathrm{x}_{1}=$ $130 \mathrm{~cm}$, yang terjadi pada belokan kanan yang terakhir dilakukan oleh operator pertama.
2. Pada lintasan 2, nilai error terbesar yaitu $\mathrm{x}_{1}=70$ $\mathrm{cm}$ yang terjadi pada tikungan dengan radius besar menuju ke tikungan dengan radius kecil. Semuanya dilakukan oleh operator pertama.

3. Rata-rata error pada lintasan 1 oleh operator 1 dan 2 yaitu 22,83 cm dan lintasan 2 yaitu 20,25 cm. Sedangakan error pada lintasan 2 dengan line follower yaitu $3,55 \mathrm{~cm}$.

4. Nilai error untuk sistem control otomatis (line follower) sistem jauh lebih kecil dibanding dengan menggunakan sistem kontrol langsung (bluethooth).

\section{DAFTAR PUSTAKA}

[1] Leena, N., \& Saju, K. K. (2016). Modelling and trajectory tracking of wheeled mobile robots. Procedia technology, 24, 538-545

[2] Lee, J. H., Lin, C., Lim, H., \& Lee, J. M. (2009). Sliding mode control for trajectory tracking of mobile robot in the RFID sensor space. International Journal of Control, Automation and Systems, 7(3), 429-435.

[3] Matraji, I., Al-Durra, A., Haryono, A., AlWahedi, K., \& Abou-Khousa, M. (2018). Trajectory tracking control of Skid-Steered Mobile Robot based on adaptive Second Order Sliding Mode Control. Control Engineering Practice, 72, 167-176.

[4] Randis, R., \& Akbar, S. (2017). Uji eksperimetal trajectory tracking pada quadcopter. DinamikaJurnal Ilmiah Teknik Mesin, 9(1).

[5] Schulz, D., Burgard, W., Fox, D., \& Cremers, A. B. (2001). Tracking multiple moving targets with a mobile robot using particle filters and statistical data association. In Robotics and Automation, 2001. Proceedings 2001 ICRA. IEEE International Conference on (Vol. 2, pp. 16651670). IEEE.

[6] Sun, S. (2005). Designing approach on trajectorytracking control of mobile robot. Robotics and Computer-Integrated Manufacturing, 21(1), 8185.

[7] Suradana, I. M., \& Sudiarsa, I. W. (2013). Pengendalian Mobile Robot Menggunakan Personal Computer Dengan Koneksi Bluetooth. Jurnal Nasional Pendidikan Teknik Informatika (JANAPATI), 2(1), 95-109

[8] Syam R, Mappaita A, et al. (2017) " Simple Design of VTOL Hexacopter for Simple Navigation." International Journal on Smart Material and Mechatronics. IJSMM.

[9] Syam, R., Ohoiwutun, J. (2013). Uji Eksperimen untuk Trajectory Tracking Mesin Pemotong Rumput Tenaga Surya. "Proceeding Seminar Nasional Tahunan Teknik Mesin XII (SNTTM XII). SNTTM. 